JURNAL KACAPURI

JURNAL KEILMUAN TEKNIK SIPIL

Volume 3 Nomor 1 Edisi Juni 2020

\title{
KAJIAN ARAHAN DAN STRATEGI PENGEMBANGAN KAWASAN POTENSIAL TRANSIT ORIENTED DEVELOPMENT (TOD) DI SEKITAR STASIUN TRANSIT LRT KOTA PALEMBANG
}

\author{
Hendry Natanael Gumano
}

\author{
Program Studi Perencanaan Wilayah \& Kota, Universitas Indo Global Mandiri \\ Jl. Jendral Sudirman No.629 Km. 4,5, Kota Palembang, Provinsi Sumatera Selatan \\ E-mail : hendrygumano@ uigm.ac.id/Hp : 082285756976
}

\begin{abstract}
ABSTRAK
Proses pembangunan di Kota Palembang dalam 10 tahun terkahir mengalami kemajuan yang sangat pesat. Dibidang infrastruktutr transportasi, inftrastruktur transportasi yang paling menarik yakni Light Rail Transit (LRT). Angkutan massal transit berbasis rel ini menarik perhatian karena tidak semua kota-kota di Indonesia memilikinya dan diyakini mampu untuk menekan permasalahan macet arus lalu lintas perkotaan dan juga lebih berkelanjutan. Terkait dengan pembangunan berkelanjutan, perlu untuk mempertimbangkan sustainable urban mobility. Berbagai pendekatan dapat dilakukan dan salah satunya dengan pengembangan kawasan berorientasi transit (Transit Oriented Development) dengan memanfaatkan layanan infrastruktur transportasi berbasi rel. TOD dinilai mampu mewujudkan keberlanjutan mobilitas warga kota menjadi lebih cepat, aman, nyaman dan terjangkau serta sekaligus berperan dalam hal membentuk ruang kota yang semakin ramah lingkungan dan teratur (Cervero, 2014). Tujuan penelitian ini untuk menentukan arahan pengembangan kawasan TOD serta strategi perwujudan kawasan TOD pada 12 stasiun transit LRT Kota Palembang. Langkah awal melalui penilaian karakteristik kawasan melalui 4 prinsi TOD yakni diversity \& destination, density, disntance \& design dan demand management. Hasil dari penialaian yakni tipologi kawasan potensial TOD Kota (1 kawasan), TOD Sub-Kota ( 6 kawasan) dan TOD Lingkungan (5 kawasan). Adapun strategi pengembangan dalam mewujudkan kawasan TOD tersebut yakni : 1). Infill Development Site untuk kawasan TOD ST. Asrama Haji dan ST. Telkom, 2). Redevelopment Site \& Infill Development Site untuk kawasan TOD ST. RSUD Prov, ST. Simp. Polda, ST. Deman, ST. Palembang Icon, ST. Diskhubkominfo, ST. Pasar Cinde, ST. Jembatan Ampera, ST. Polrestabes. 3). New Growth Area untuk kawasan TOD ST. Jakabaaring, ST. OPI Mall.
\end{abstract}

Kata Kunci : Kawasan Berorientasi Transit (TOD), LRT, Pengembangan TOD, Integrasi Guna Lahaan \& Transportasi

\begin{abstract}
The development process in the city of Palembang in the last ten years experienced very rapid progress. In the transportation infrastructure field, the most interesting transportation infrastructure is Light Rail Transit (LRT). This rail-based mass transit has attracted attention because not all cities in Indonesia have it and are believed to reduce the problem of urban traffic congestion and
\end{abstract}


is also more sustainable. Related to sustainable development, it is necessary to consider sustainable urban mobility. Various approaches can be taken, and one of them is by developing transit-oriented areas (Transit Oriented Development) by utilizing rail-based transportation infrastructure services. TOD is considered capable of realizing sustainable mobility of city residents that is faster, safer, more convenient, and affordable. At the same time, it plays a role in shaping urban space that is increasingly environmentally friendly and orderly (Cervero, 2014). This study aimed to determine the direction of the development of the TOD area and the strategy of the realization of the TOD area at 12 Palembang LRT transit stations. The initial step is to assess the characteristics of the region through the 4 TOD principles, namely diversity \& destination, density, distance \& design, and demand management. The results of the assessment are a typology of the potential area of City TOD (1 region), Sub-City TOD (6 regions), and Environmental TOD (5 regions). The development strategy in realizing the TOD area, namely: 1). Infill Development Site for the TOD ST area. Hajj Dormitory and ST. Telkom, 2). Redevelopment Site \& Infill Development Site for the TOD ST area. RSUD Prov, ST. Simp. Polda, ST. Deman, ST. Palembang Icon, ST. Diskhubkominfo, ST. Cinde Market, ST. Ampera Bridge, ST. Polrestabes. 3). New Growth Area for the TOD ST. Jakabaaring, ST. OPI Mall.

Keywords: Transit-Oriented Development (TOD), LRT, TOD Development, Land Use Integration \& Transportation

\section{PENDAHULUAN}

Menurut Cervero (2014), integrasi infrastruktur transportasi seperti pengembangan BRT sampai saat ini dinilai masih belum optimal dalam menciptakan ciri pembangunan yang kompak dan multi-guna. Hal ini dikarenakan jalur dan terminal yang penempatanya masih pada jalur-jalur yang relatif sibuk. Untuk itu, diperlukan suatu konsep pembangunan yang harus berorientasi pada transit selain dari pengembangan moda angkutan BRT yang sudah ada dalam upaya untuk menciptakan proses urbanisasi yang berkelanjutan.

Pengembangan dan pembangunan LRT di Kota Palembang sudah mulai dilakukan dengan rencana panjang trase $\pm 23 \mathrm{~km}, 13$ stasiun dan 1 depo. Koridor yang dilalui oleh LRT sebagian besar masuk kedalam wilayah administrasi Kota Palembang. Urgenitas pengembangan dan pembangunan sistem transportasi LRT di Kota Palembang tidak lepas dari peran Kota Palembang sebagai tuan rumah pergelaran ASIAN GAMES pada Agustus 2018. Diharapkan akan mampu menjamin kelancaran mobilitas para atlet yang ikut berlaga hingga official tim yang ikut terlibat dalam pesta olahraga negara-negara se-Asia tersebut.

Dalam proses pertumbuhan kota yang semakin pesat dan terus berkembang diyakini akan menimbulkan gejala urban sprawl karena salah satunya keterbatasan dari lahan perkotaan tersebut (El et al. 2017). Hal ini tentu saja memberikan dampak terhadap volume lalu lintas dengan kendaraan pribadi yang semakin meningkat karena persebaran pembangunan diperkotaan yang tidak jelas dan belum terintegrasi dengan sistem transportasi yang baik. Keberadaan LRT harus dianggap sebagai suatu sarana dan prasarana transportasi yang menjadi cikal bakal dalam mendukung pembangunan berkelanjutan wilayah Kota Palembang di Provinsi Sumatera Selatan. Manajemen pertumbuhan kota yang berkelanjutan (managing sustainable urban growth) diharapkan menjadi suatu solusi dan sudah sering diterapkan dibanyak negara (Van, 2017). 
Menciptakan tatanan transportasi yang lebih efisien sehingga mendorong terciptanya aksesibilitas dan mobilitas kegiatan penduduk yang lebih baik menjadi fokus dari pembangunan (Kustiwan, 2011). Hal ini dapat dilakukan melalui integrasi tata guna lahan dengan transportasi berbasis transit untuk mengatasi gejala urban sprawl yang akan terjadi serta menekan ketergantungan terhadap penggunaan kendaraan pribadi.

Integrasi tata guna lahan yang berbasis transit tersebut salah satunya dengan penerapan pendekatan Transit Oriented Development (TOD) (Suzuki et al, 2013). Daerah transit yang paling berpotensi memberikan manfaat berkelanjutan paling tinggi yaitu kawasan dengan sistem transportasi moda angkutan massal berbasiskan rel, sebab kawasan ini mengalami pergantian moda transportasi umum yang sangat intensif dan tinggi serta sangat cocok untuk diterapkan konsep integrasi berbasis TOD (Feudo, 2014 \& Buletin Tata Ruang edisi 2, 2017). Melalui pendekatan TOD, kawasan ini akan berkembang dengan bertumpu pada sistem angkutan massal, menjadi kawasan campuran dengan kepadatan, keragaman serta intensitas pemanfaatan ruang dari sedang ke tinggi. Kawasan dengan konsep TOD ini diharapkan akan mendorong pengurangan penggunaan kendaraan bermotor dan energi transportasi serta mendorong meningkatnya interaksi sosial yang semuanya dikemas untuk menciptakan kawasan ramah lingkungan di dalam kota.Secara umum, pada prinsipnya penerapan konsep TOD ditujukan untuk mencegah perkembangan kota yang tidak berkelanjutan, mengendalikan tumbuhnya perkembangan kota yang secara acak dan tidak terencana (urban sprawl), serta mengurangi frekuensi penggunaan kendaraan pribadi (Van, 2017). Oleh karena itu, rencana pengembangan dan keberadaan LRT ini dianggap sebagai suatu peluang, peluang yang harus ditangkap dan dipikirkan penerapannya untuk mendukung pembangunan berkelanjutan di wilayah Kota Palembang.

Berdasarkan penjelasan permasalahan diatas, maka tujuan penelitian ini adalah mengeksplorasi dan menganalisis tipologi dan arahan strategi pengembangan TOD pada kawasan titik-titik transit koridor LRT Kota Palembang. Melalui ini dapat diketahui sejauh mana kesiapan dan gambaran pengembangan dari kawasan yang menjadi titik transit tersebut untuk diintegrasikan dengan layanan transportasi publik LRT Kota Palembang dengan Konsep TOD.

\section{METODE PENELITIAN}

Teknik Pengumpulan Data : Pengumpulan data pada tahapan survei lapangan menggunakan dua metode survei. Pertama yaitu survei primer atau lapangan untuk mendapatkan data primer dan kedua yaitu survei sekunder atau instansional untuk mendapatkan data sekunder.

Survei primer dilakukan untuk mendapatkan data lapangan dengan cara pengamatan langsung atau observasi, dokumentasi hingga beberapa wawancara tidak terstruktur dilapangan (kawasan objek studi). Observasi dilakukan menggunakan bantuan form survei lapangan. Form survei lapangan yang digunakan memuat 14 variabel beserta indikator penilain. 14 variabel penilaian berserta indikator penilaian tersebut digunakan untuk menggambarkan tingkat ketercapaian karakteristik TOD di kawasan studi. Lokasi kawasan potensial TOD yang diamati yakni pada area dalam ukuran radius 800 meter dari titik transit Stasiun LRT. 
Teknik Pengolahan Data : Adapun beberapa teknik analisis yang digunakan dalam penelitian ini antara lain berupa analisis deskriptif kuantitatif. Dengan teknik ini akan bertujuan untuk mendeskripsikan situasi area kawasan titik transit LRT yang menjadi objek studi berdasarkan sifat faktual secara sistematis dan akurat. Pemahaman karakteristik kawasan yang menjadi objek studi dan kemudian berdasarkan variabel dan tolak ukur penelitian akan dibantu dengan keterangan checklist, peta, foto, hasil pengukuran dan benar-benar menyajikan data sebagaimana nampak dilapangan. Hasilnya kemudian diharapkan dapat menjadi justifikasi kondisi dan keadaan untuk keperluan perencanaan, pengembangan dan operasional TOD kedepannya.

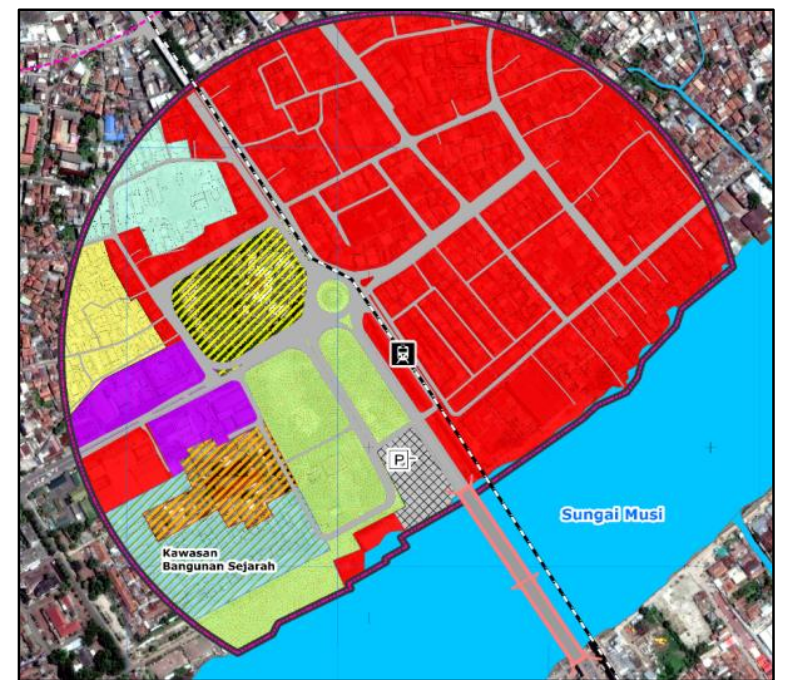

Gambar 1. Salah Satu Wilayah Studi Amatan Kawasan Potensial TOD Radius 800 meter.

(Contoh : Kawasan Sekitar ST. Jembatan Ampera) 
JURNAL KACAPURI

JURNAL KEILMUAN TEKNIK SIPIL

Volume 3 Nomor 1 Edisi Juni 2020

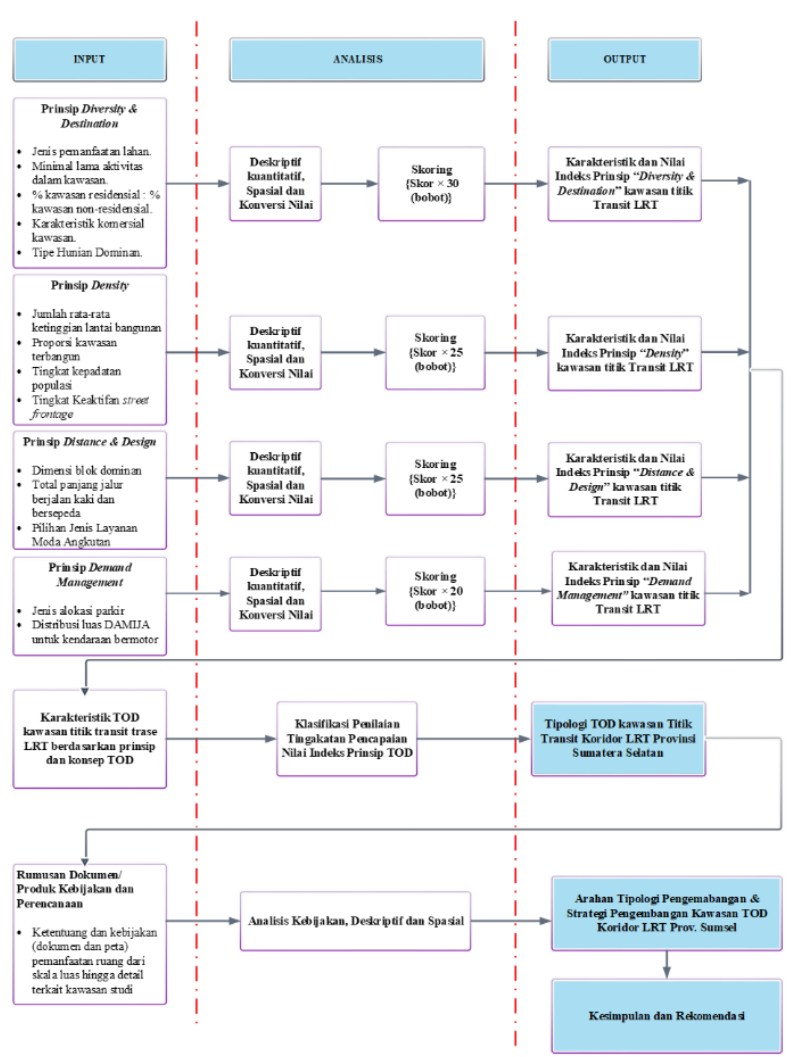

Gambar 2. Kerangka Analisis

\section{HASIL \& PEMBAHASAN}

\section{Identifikasi Karaktersitik Kawasan Potensial TOD}

Menurut acuan normatif Permen ATR/ BPN Nomor 16 tahun 2017 tetang pengembangan kawasan berorientasi transit (TOD) dikalsifikasikan menjadi :

- TOD Kota - Pusat Pelayanan Kota;

- TOD Sub Kota - Sub Pusat Pelayanan Kota; dan

- TOD Lingkungan - Pusat Pelayanan Lingkungan

\section{Diversity \& Destination}

Dalam perwujudan TOD, diversity \& destination pada prinsipnya adalah untuk mewujudkan dan menjamin berbagai jenis aktivitas kegiatan terdapat dan mudah dijangkau pada sekitaran kawasan titik transit. Dalam hal ini beberapa hal penting yang merupakan aspek untuk menjamin tercapainya prinsip daripada diversity \& destination antara lain penialaian pada variabel 1). Jenis aktivitas pemanfaatan lahan; 2). Minimal lama aktivitas dalam kawasan; 3). Perbandingan persentase kawasan residensial dengan kawasan nonresidensial; 4). Karakteristik komersial kawasan; dan 5). Tipe huniannya. 
JURNAL KACAPURI

JURNAL KEILMUAN TEKNIK SIPIL

Volume 3 Nomor 1 Edisi Juni 2020

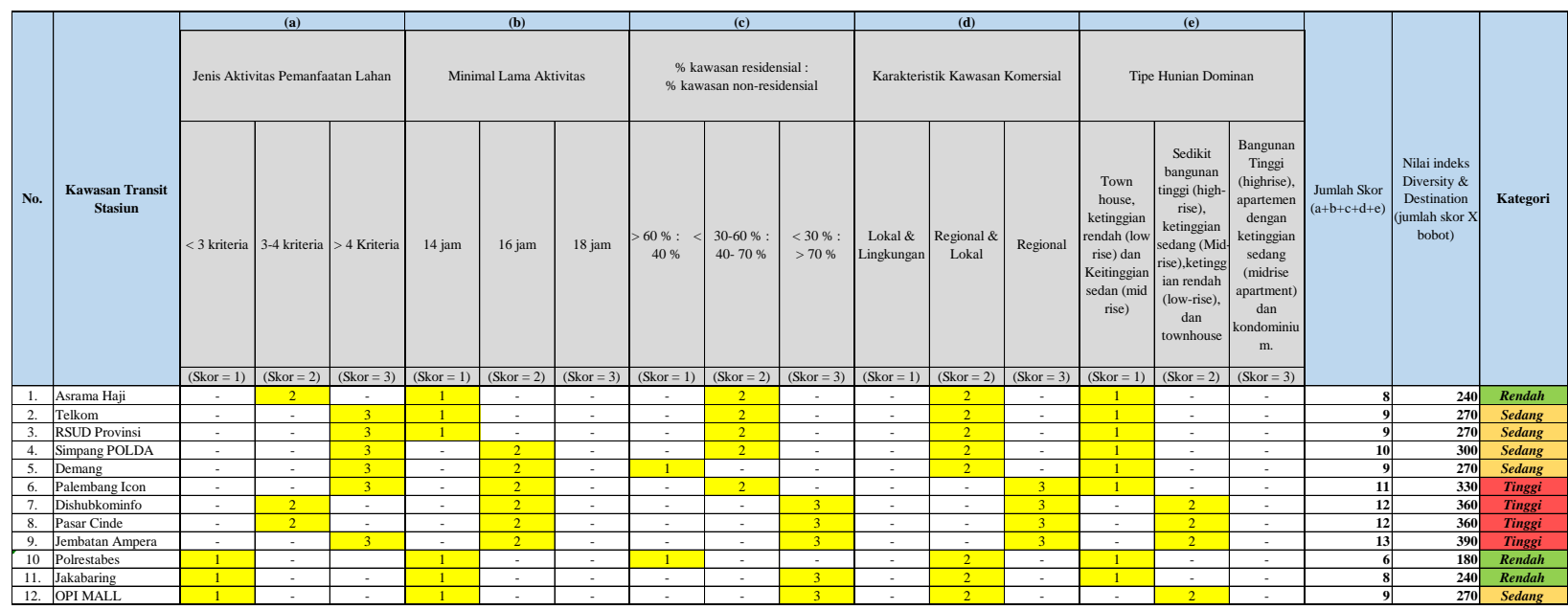

Tabel 1. Hasil Penilaian Diversity \& Destination

\section{Density}

Prinsip TOD selanjutnya adalah density yang berkaitan dengan bagaimana menciptakan suatu ruang, lahan dalam suatu kawasan transit menjadi lebih kompak untuk dimanfaatkan dan digunakan seoptimal mungkin sehingga dapat menjadi salah satu faktor pendukung dalam hal menampung, melayani dan memfasilitasi segala jenis kegiatan/ aktivitas didalamnya dengan kapasitas yang maksimal tentunya. Singkatnya, dengan prinsip TOD berdasarkan density yaitu mengintensifkan pertumbuhan dan pembangunan dalam kawasan dari sedang ke tinggi sehingga terbentuklah lingkungan berbasis transit yang padat dan terpusat.

Oleh karena itu, terdapat beberapa aspek yang kemudian akan digunakan sebagai variabel penilaian perwujudan density suatu kawasan transit yang kemudian akan dikembangkan dengan pendekatan TOD, antara lain : 1). Jumlah lantai bangunan, 2). Proporsi kawasan terbangun, 3). Kepadatan populasi, dan 4). Street Frontage (Keaktifan Muka Bangunan).

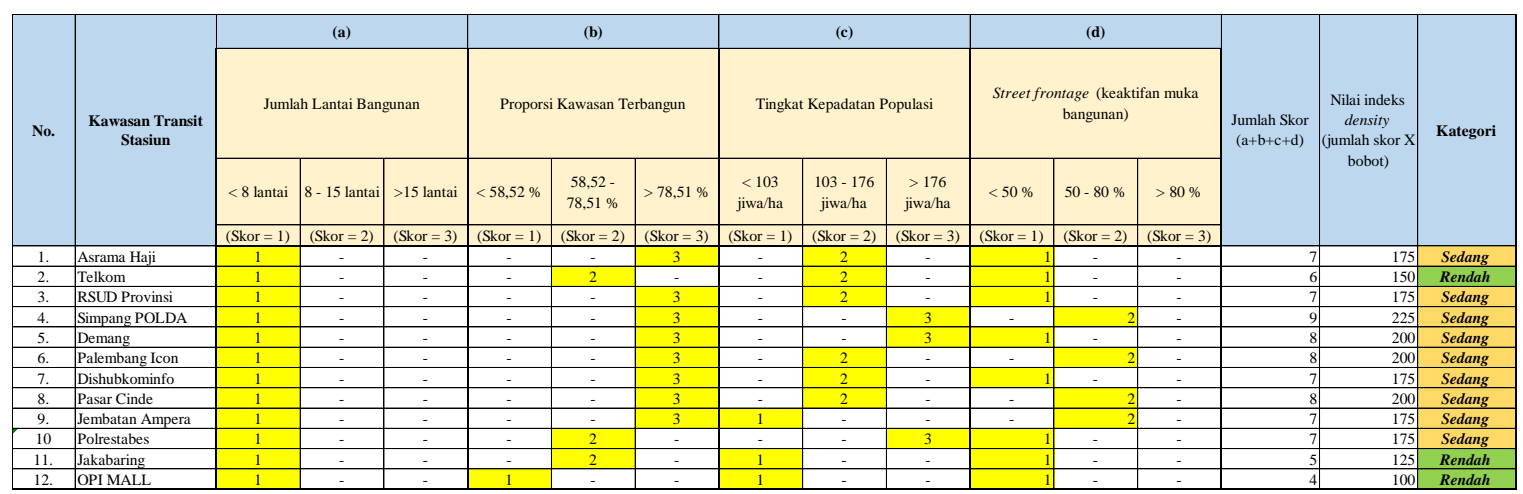

Tabel 2. Hasil Penilaian Density

\section{Distance \& Design}

Pada prinsip distance $\&$ design adalah bagaimana untuk mewujudkan ruang-ruang dalam kawasan TOD menjadi kompak, menarik serta terhubung dengan singkat satu dengan yang lain sehingga dapat memperpendek jangkauan dan jarak tempuh yang berpengaruh pada konektivitas/ aksesibiltas yang tinggi dari dan ke lokasi transit atau tujuan lainnya yang 
aman dan nyaman sehingga meningkatkan minat melakukan pergerakan tanpa kendaraan bermotor (pribadi).

Terdapat beberapa variabel yang menjadi penilaian untuk melihat perwujudan TOD berdasarkn pada prinsip distance \& design antara lain 1). Dimensi blok, 2). Total jalur berjalan kaki/ bersepeda, dan 3). Pilihan jenis moda angkutan.

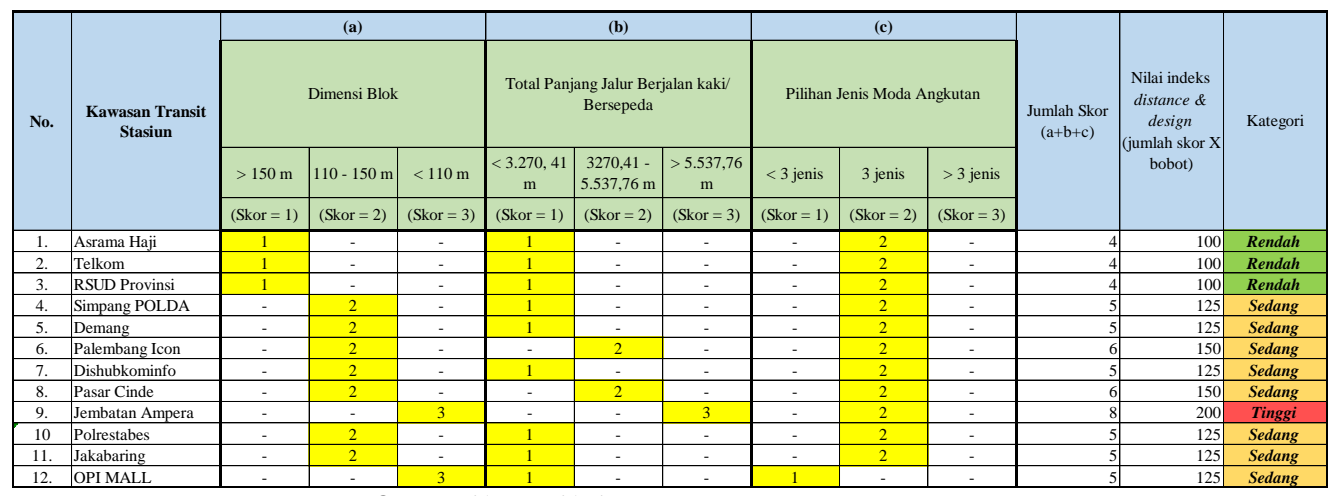

Tabel 3. Hasil Penilaian Distance \& Design

\section{Demand Management}

Demand management dianggap juga sebagai upaya untuk mewujudkan reduce motorize yang artinya berbagai upaya untuk menekan ketergantungan serta pemakaian kendaraan bermotor dalam kawasan TOD serta meningkatkan minat untuk melakukan perjalanan yang bersifat transit. Salah satunya melalui pengaturan distribusi ruas jalan yang tidak hanya untuk moda bermotor saja, menejemen sistem parkir pada dalam kawasan TOD dan beberapa lainnya. Adapun variabel penilaian untuk perwujudan prinsip TOD berdasarkan demand management antara lain 1). Alokasi parkir dan 2). Distribusi daerah milik jalan (damija) untuk kendaraan bermotor.

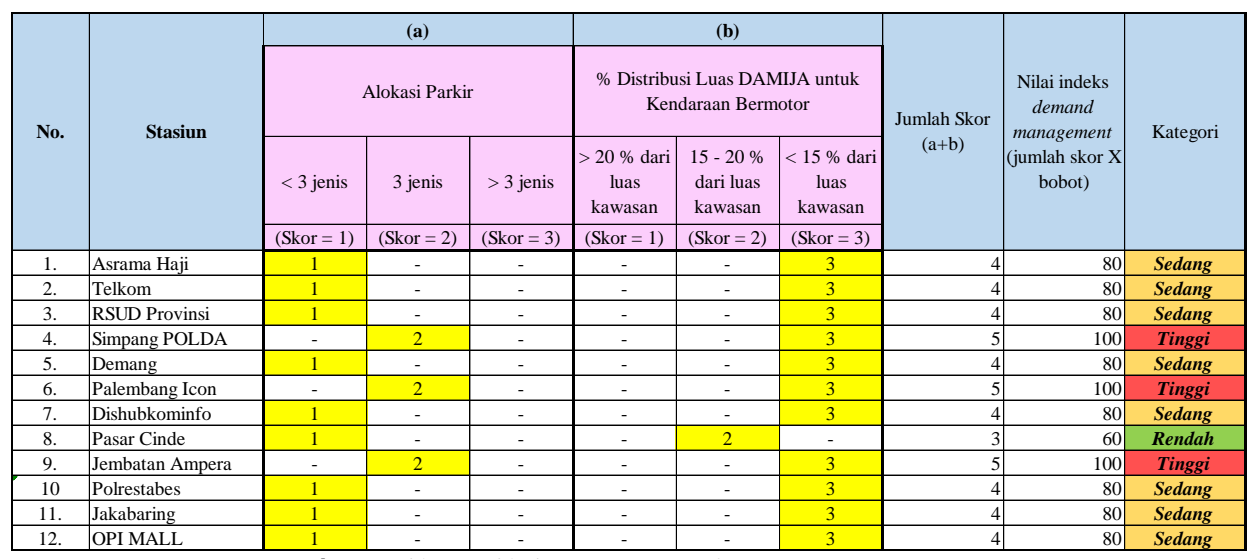

Tabel 4. Hasil Penilaian Demand Management

\section{Kecenderungan Tipologi Kawasan Potensial TOD}

Penialaian kecenderungan tipologi pengembangan TOD dilakukan sebagai langkah dalam hal identifikasi arah pengembangan sifat dan ciri kawasan transit sesuai dengan tipologi dan klasifikasi TOD yaitu kawasan 1). TOD Kota-Pusat Pelayanan Kota, 2). TOD Sub Kota-Sub Pusat Pelayanan 
Kota dan 3). TOD Lingkungan-Pusat Pelayanan Lingkungan. Untuk melihat kecenderungan tersebut dengan melakukan tindak lanjut dari pada penialaian kondisi eksisiting kawasan transit yang berdasarkan prinsip dan variabel TOD pada sub-bab sebelumnya yang dalam hal ini disebut sebagai nilai indeks karakterisktik prinsip TOD kawasan Transit.

Apabila seluruh variabel penilaian pada setiap prinsip TOD nilai skor nya paling rendah semuanya setelah dikali bobot maka untuk nilai indeks totalnya yaitu 365 (nilai minumum) sedangkan sebaliknya nilai indeks totalnya yaitu 1.095 (nilai maksimum). Nilai indeks tekecil dan terbesar ini kemudian digunakan dalam menentukan rentan nilai pada ke-3 tipologi TOD yang hasilnya antara lain :

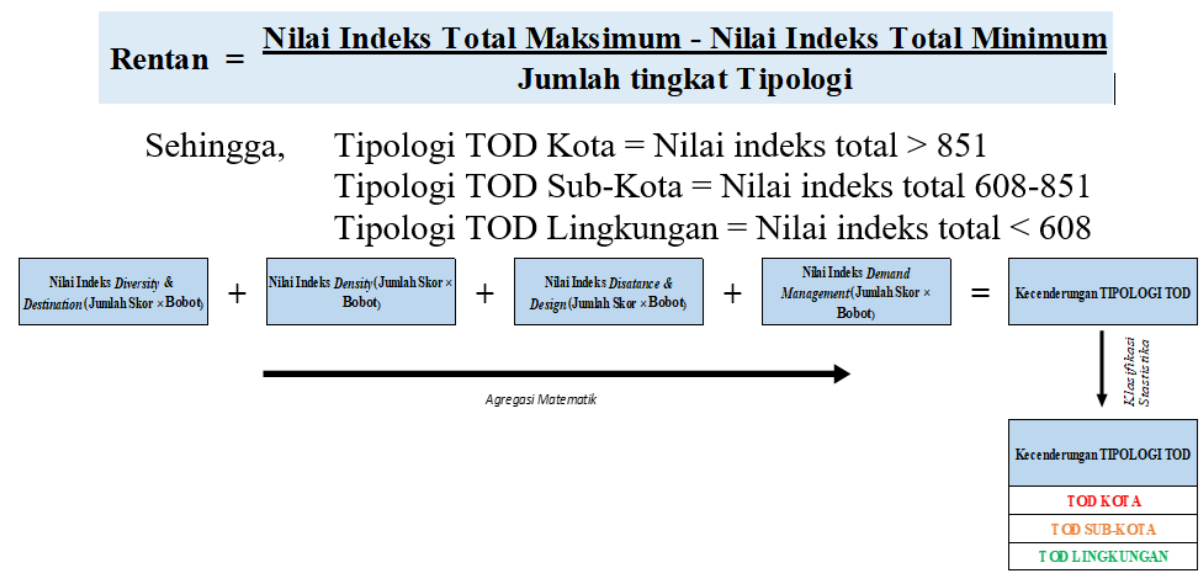

Sehingga kecenderungan tipologi Kawasan Potensial TOD Kota Palembang adalah sebagai berikut :

\begin{tabular}{|c|c|c|c|c|c|c|c|}
\hline \multirow[b]{2}{*}{ No. } & \multirow[b]{2}{*}{ Stasiun } & \multicolumn{4}{|c|}{ Nilai Indeks Prinsip TOD } & \multirow[b]{2}{*}{$\begin{array}{c}\text { Nilai Indeks } \\
\text { Total }\end{array}$} & \multirow[b]{2}{*}{$\begin{array}{c}\text { Kecenderungan } \\
\text { Tipologi TOD }\end{array}$} \\
\hline & & $\begin{array}{l}\text { Diversity \& } \\
\text { Destination }\end{array}$ & Density & $\begin{array}{c}\text { Distance \& } \\
\text { Design }\end{array}$ & $\begin{array}{c}\text { Demand } \\
\text { Management }\end{array}$ & & \\
\hline 1. & Asrama Haji & 240 & 175 & 100 & 80 & 595 & TOD Lingkungan \\
\hline 2. & Telkom & 270 & 150 & 100 & 80 & 600 & TOD Lingkungan \\
\hline 3. & RSUD Provinsi & 270 & 175 & 100 & 80 & 625 & TOD Sub-Kota \\
\hline 4. & Simpang POLDA & 300 & 225 & 125 & 100 & 750 & TOD Sub-Kota \\
\hline 5. & Demang & 270 & 200 & 125 & 80 & 675 & TOD Sub-Kota \\
\hline 6. & Palembang Icon & 330 & 200 & 150 & 100 & 780 & TOD Sub-Kota \\
\hline 7. & Dishubkominfo & 360 & 175 & 125 & 80 & 740 & TOD Sub-Kota \\
\hline 8. & Pasar Cinde & 360 & 200 & 150 & 60 & 770 & TOD Sub-Kota \\
\hline 9. & Jembatan Ampera & 390 & 175 & 200 & 100 & 865 & TOD Kota \\
\hline 10. & Polrestabes & 180 & 175 & 125 & 80 & 560 & TOD Lingkungan \\
\hline 11. & Jakabaring & 240 & 125 & 125 & 80 & 570 & TOD Lingkungan \\
\hline 12. & OPI MALL & 270 & 100 & 125 & 80 & 575 & TOD Lingkungan \\
\hline
\end{tabular}

Tabel 5. Hasil Penilaian Kecenderungan Kawasan Potensial TOD Kota Palembang

\section{Analisis Hubungan Kecenderungan Tipologi TOD Kawasan Transit dengan Arahan Rencana Pemanfaatan Ruang}

Tipologi TOD ini adalah sebagai upaya untuk memberikan gambaran awal dan fokus pengembangan kawasan transit dengan konsep TOD pada tahap perencanaan, desain hingga operasionalnya (Kamruzzaman et,al, 2014; Lyu, 2016). Maka untuk itu, perlu untuk memperhatikan beberapa arahan pemanfaatan ruang yang sudah ada sebagai upaya dalam 
sinkronisasi untuk menghindari tumpang tindih arah pengembangan dan pemanfaatan ruangnya khususnya pada rencana struktur ruang.

Penilaian kesesuaiannya menggunakan indikasi daripada kesamaan fungsi klasifikasi/ tipologi TOD dan rencana pusat pelayanan (struktur ruang), antara lain sebagai berikut :

- TOD Kota menurut fungsinya akan sesuai dengan Pusat Pelayanan Kota (Struktur Ruang RTRW) yang merupakan pengembangan kawasan sebagai pusat perekonomian berfungsi primer dan budaya regional;

- TOD Sub-Kota menurut fungsinya akan sesuai dengan Sub Pusat Pelayanan Kota (Struktur Ruang RTRW) yang merupakan pengembangan kawasan sebagai pusat perekonomian, khususnya yang berfungsi sekunder dan budaya regional dan ;

- TOD Lingkungan menurut fungsinya akan sesuai dengan Pusat Pelayanan Lingkungan (Struktur Ruang RTRW) yang merupakan pengembangan kawasan sebagai pusat aktivitas ekonomi lokal dan komunitas lokal.

\begin{tabular}{|c|c|c|c|c|}
\hline No. & $\begin{array}{c}\text { Kawasan Transit } \\
\text { Stasiun }\end{array}$ & $\begin{array}{c}\text { Kecenderungan } \\
\text { Tipologi TOD }\end{array}$ & $\begin{array}{c}\text { Arahan Rencana Tata } \\
\text { Ruang (RTRW) }\end{array}$ & $\begin{array}{l}\text { Kesesuaian } \\
\text { (Ya/ Tidak) }\end{array}$ \\
\hline 1. & Asrama Haji & TOD Lingkungan & Sub PPK Sukarami & Tidak \\
\hline \multirow[t]{2}{*}{2.} & \multirow[t]{2}{*}{ Telkom } & \multirow[t]{2}{*}{ TOD Lingkungan } & Sub PPK Sukarami & \multirow[b]{2}{*}{ Tidak } \\
\hline & & & $\begin{array}{l}\text { Sub PPK Alang-alang } \\
\text { Lebar } \\
\end{array}$ & \\
\hline \multirow[t]{2}{*}{3.} & \multirow[t]{2}{*}{ RSUD Provinsi } & \multirow[t]{2}{*}{ TOD Sub-Kota } & Sub PPK Sukarami & \multirow[b]{2}{*}{$Y a$} \\
\hline & & & $\begin{array}{l}\text { Sub PPK Alang-alang } \\
\text { Lebar }\end{array}$ & \\
\hline 4. & Simpang POLDA & TOD Sub-Kota & PPK Pusat Kota & Tidak \\
\hline \multirow[t]{2}{*}{5.} & \multirow[t]{2}{*}{ Demang } & \multirow[t]{2}{*}{ TOD Sub-Kota } & $\begin{array}{l}\text { Sub PPK Alang-alang } \\
\text { Lebar }\end{array}$ & \multirow{2}{*}{$Y a$} \\
\hline & & & PPK Pusat Kota & \\
\hline 6. & Palembang Icon & TOD Sub-Kota & PPK Pusat Kota & Tidak \\
\hline 7. & Dishubkominfo & TOD Sub-Kota & PPK Pusat Kota & Tidak \\
\hline 8. & Pasar Cinde & TOD Sub-Kota & PPK Pusat Kota & Tidak \\
\hline 9. & Jembatan Ampera & TOD Kota & PPK Pusat Kota & $Y a$ \\
\hline 10. & Polrestabes & TOD Lingkungan & PPK Jakabaring & Tidak \\
\hline 11. & Jakabaring & TOD Lingkungan & PPK Jakabaring & Tidak \\
\hline 12. & OPI MALL & TOD Lingkungan & PPK Jakabaring & Tidak \\
\hline
\end{tabular}

Tabel 6. Penilaian Kesesuaian Kecenderungan Tipologi TOD Pada Arahan Rencana Tata Ruang (RTRW)
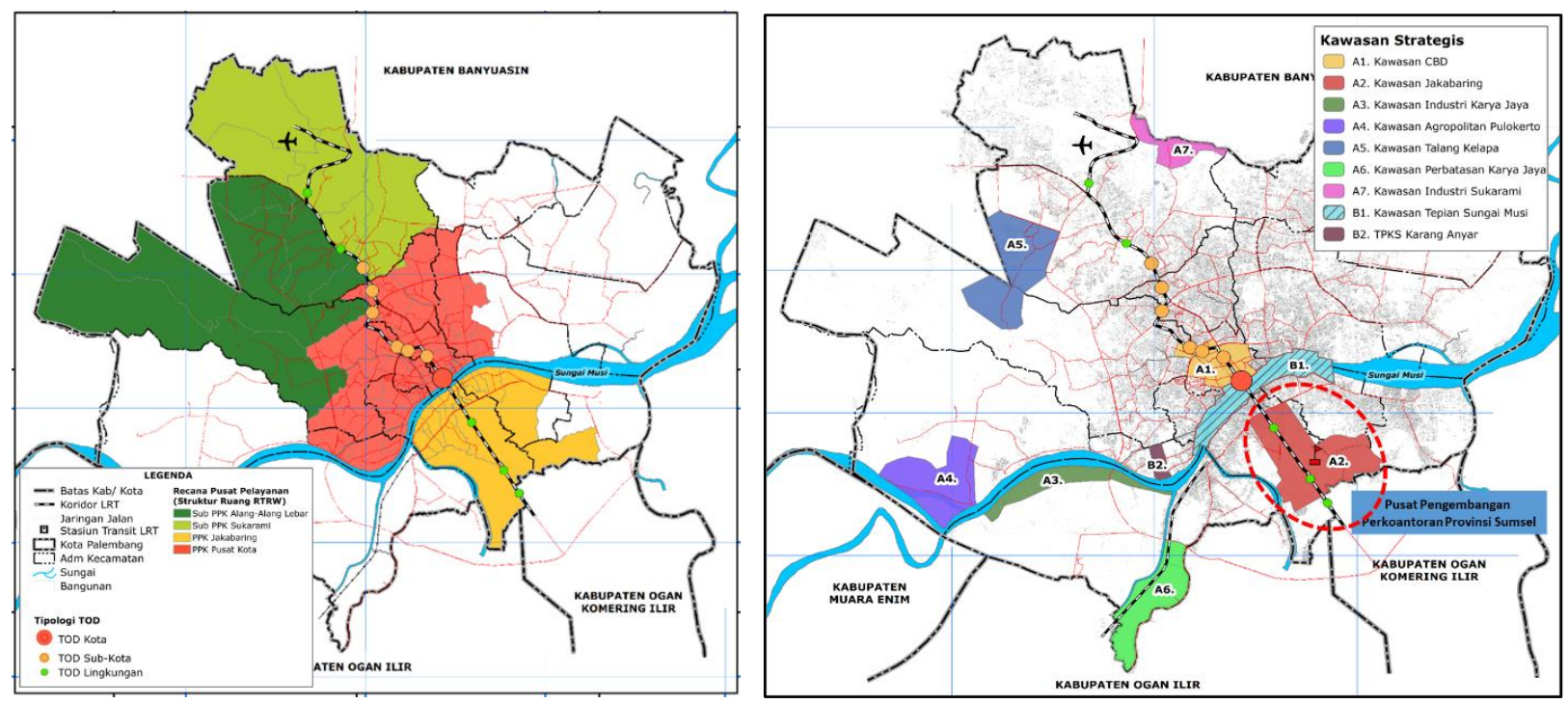
Gambar 3. Kedudukan Kecenderungan

Tipologi TOD terhadap Arahan Pusat Pelayanan dalam Rencana Tata Ruang (RTRW)
Gambar 4. Kedudukan Kecenderungan Tipologi TOD terhadap Arahan Kawasan Strategis dalam Rencana Tata Ruang (RTRW)

Berdasarkan hasil penilaian sinkronisasi, dapat terlihat bahwa dari 12 kawasan stasiun yang dinilai arahan pada rencana tata ruangnya, terdapat 3 (tiga) kawasan yang sesuai dengan hasil kecenderungan tipologi TOD sedangkan 9 (sembilan) kawasan stasiun lainnya tidak sesuai dan seharusnya pada arahan pengembangan TOD, kecenderungan tipologi TOD adalah suatu rekomendasi pengembangan yang akan dipilih pada 12 kawasan transit tersebut, dan pada kawasan transit yang belum sesuai perlu untuk menyesuaiakan terhadap arahan kecenderungan tipologi TOD tersebut.

Namun, sebelum menetapkan arahan pengembangan TOD yang seharusnya mutlak mengikuti hasil penilaian kecenderungan tipologi TOD (karena telah dinilai berdasarkan prinsip-prinsip TOD), terdapat juga pertimbangan lain antara lain :

- Pada kawasan transit stasiun 1). Polrestabes, 2). Jakabaring dan 3). OPI Mall. Pada hasil kecenderungan tipologi TOD nya adalah sebagai TOD Lingkungan karena memang dari hasil pencapaian pada setiap varabel prinsip TOD dominan dengan pencapaian paling rendah.

- Hanya saja, mendapatkan pencapaian paling rendah juga dipengaruhi oleh faktor kawasan tersebut pada kondisi eksisitingnya belum terbangun dan terkadang untuk parameter prinsip TOD yang diamati tidak terdapat dilapangan dan mendapat nilai rendah (mungkin akan beda pencapaiannya bila sudah terbangun sama seperti kawasan transit lainnya).

- Sebagaimana dijelaskan juga sebelumnya pentingnya untuk melakukan sinkronisasi dengan arahan pemanfaatan ruang, pada ke 3 (tiga) kawasan transit ini diharapkan tidak hanya menjadi pusat pelayanan lingkungan/lokal melainkam sebagai Pusat Pelayanan khususnya untuk Kawasan Jakabaring.

- Maka oleh 3 hal diatas, hal ini mendasari justifikasi untuk menetapkan arahan pengembangan TOD di 3 kawasan transit tersebut tidak mutlak mengikuti hasil kecenderungan tipologi TOD sebagai TOD Lingkungan, melainkan dinaikkan menjadi TOD Sub-Kota.

Sehingga, arahan potensi pengembangan kawasan TOD pada kawasan transit koridor LRT Kota Palembang di Kota Palembang adalah sebanyak 1 (satu) kawasan transit sebagai TOD Kota, 9 (sembilan) kawasan transit TOD Sub-Kota dan 2 (dua) kawasan transit sebagai TOD Lingkungan. Sebarannya adalah sebagai berikut : 
JURNAL KACAPURI

JURNAL KEILMUAN TEKNIK SIPIL

Volume 3 Nomor 1 Edisi Juni 2020

\begin{tabular}{|c|c|c|}
\hline No. & $\begin{array}{c}\text { Arahan Tipologi } \\
\text { Pengembangan TOD }\end{array}$ & Kawasan Transit Stasiun \\
\hline 1. & TOD KOTA & Jembatan Ampera \\
\hline 2. & \multirow{9}{*}{ TOD SUB-KOTA } & RSUD Provinsi \\
\hline 3. & & Simpang POLDA \\
\hline 4. & & Demang \\
\hline 5. & & Palembang Icon \\
\hline 6. & & Dishubkominfo \\
\hline 7. & & Pasar Cinde \\
\hline 8. & & Polrestabes \\
\hline 9. & & Jakabaring \\
\hline 10. & & OPI MALL \\
\hline 11. & \multirow{2}{*}{ TOD LINGKUNGAN } & Asrama Haji \\
\hline 12. & & Telkom \\
\hline
\end{tabular}

Tabel 7. Potensi Arahan Pengembangan TOD Kawasan Transit LRT Kota Palembang

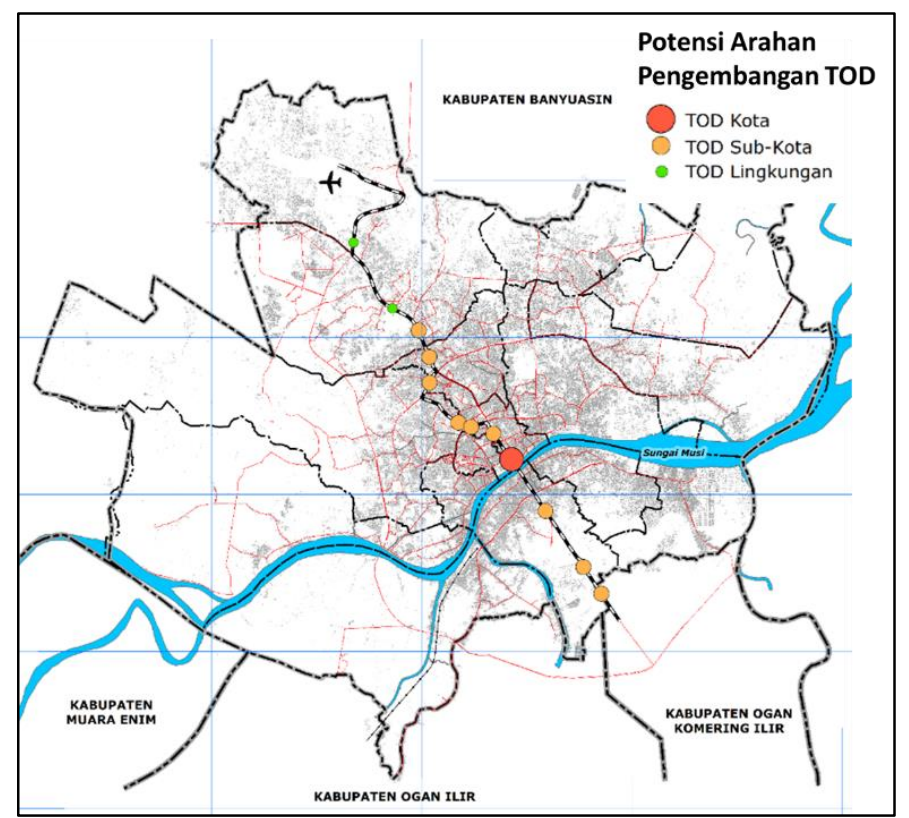

Gambar 5. Potensi Arahan Pengembangan TOD

\section{Peningkatan Performa Kawasan TOD Berdasarkan Kategori Prinsip TOD}

Setelah potensi arahan kawasan untuk dikembangkan menjadi TOD sudah ditentukan, tentunya diperlukan beberapa perbaikan. Perbaikan yang dimaksud yaitu terkait dengan performa kawasan menurut prinsip-prinsip TOD. Arahan peningkatan performa ini didapatkan dari hasil analisis penilaian karakteristik kawasan serta disandingkan dengan standar perwujudan kawasan TOD.

Idealnya untuk pengembangan kawasan transit sebagai TOD Kota perlu diupayakan pengembangan dan peningkatan terhadap prinsip TOD-nya supaya pencapaiannya masuk dan bernilai kedalam kategori tinggi. Untuk pengembangan kawasan transit sebagai TOD Sub-Kota, perlu diupayakan pengembangan dan peningkatan setiap pencapaian prinsip TOD-nya masuk dan bernilai dalam kategori sedang. 


\begin{tabular}{|c|c|c|c|c|c|c|}
\hline \multirow{2}{*}{ No. } & \multirow{2}{*}{$\begin{array}{c}\text { Arahan Tipologi } \\
\text { Pengembangan TOD }\end{array}$} & \multirow{2}{*}{$\begin{array}{c}\text { Kawasan Transit } \\
\text { Stasiun }\end{array}$} & \multicolumn{3}{|c|}{ Kategori Penilaian Prinsip TOD } & \multirow{2}{*}{ Keterangan } \\
\hline & & & Rendah & Sedang & Tinggi & \\
\hline 1. & TOD KOTA & Jembatan Ampera & - & 24 & (1) 34 & \multirow{12}{*}{$\begin{array}{l}\text { (1) }=\text { Diversity \& Destination } \\
2=\text { Density } \\
3=\text { Distance \& Design } \\
4=\text { Demand Management }\end{array}$} \\
\hline 2. & \multirow{9}{*}{ TOD SUB-KOTA } & RSUD Provinsi & 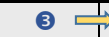 & (1) 24 & - & \\
\hline 3. & & Simpang POLDA & - & (1) 23 & 4 & \\
\hline 4. & & Demang & - & (1) 234 & - & \\
\hline 5. & & Palembang Icon & - & 23 & (1) 4 & \\
\hline 6. & & Dishubkominfo & - & 234 & (1) & \\
\hline 7. & & Pasar Cinde & (4) & 23 & (1) & \\
\hline 8. & & Polrestabes & (1) & 234 & - & \\
\hline 9. & & Jakabaring & (1) 2 & 34 & - & \\
\hline 10. & & OPI MALL & 2 (2) & (1) 34 & - & \\
\hline 11. & \multirow{2}{*}{ TOD LINGKUNGAN } & Asrama Haji & (1) 3 & 24 & - & \\
\hline 12. & & Telkom & (2) 3 & (1) 4 & - & \\
\hline
\end{tabular}

Tabel 8. Arahan Peningkatan Performa Kawasan Potensial TOD

\section{Strategi Perwujudan Pengembangan Kawasan TOD}

Selain daripada arahan peningkatan performa, penting juga untuk merumuskan pendekatan awal sebagai startegi awal dalam perwujudan pengembangan kawasan TOD di Kota Palembang. Menurut Calthorpe (1993) terdapat 3 strategi pengembangan kawasan TOD antara lain 1). Redevelopment Site yakni semacam peremajaan dengan menambah fungsi baru konsep TOD, 2). Infill development site yakni melakukan pembangunan dengan konsep TOD pada beberapa ruang kosong dalam kawasan dan 3). New Growth Area yakni dengan pembangunan baru dengan konsep TOD pada kawasan yang relatif masih kosong.

\begin{tabular}{|c|c|c|c|}
\hline No. & Kawasan Transit & $\begin{array}{c}\text { Strategi } \\
\text { Pengembangan } \\
\text { Kawasan }\end{array}$ & Pertimbangan Penilaian \\
\hline 1 & ST. Asrama Haji & \multirow[t]{2}{*}{$\begin{array}{l}\text { Infill development } \\
\text { Site }\end{array}$} & \multirow{2}{*}{$\begin{array}{l}\text { Dengan memperhatikan kondisi kawasan eksisting } \\
\text { kawasan yang masih memiliki sedikit ruang-ruang } \\
\text { kosong untuk pengembangan dengan konsep TOD } \\
\text { serta arahan tipologi pengembangan TOD yang } \\
\text { termasuk dalam TOD Lingkungan maka tidak } \\
\text { terlalu mengubah kondisi dan fungsi kawasan } \\
\text { dominan saat ini (dominan dengan fungsi } \\
\text { permukiman). }\end{array}$} \\
\hline 2 & ST. Telkom & & \\
\hline 3 & ST. RSUD Provinsi & \multirow{8}{*}{$\begin{array}{c}\text { Redevelopment Site } \\
\text { \& Infill } \\
\text { Development Site }\end{array}$} & \multirow{8}{*}{$\begin{array}{l}\text { Arahan tipologi pegembangan TOD yang termasuk } \\
\text { pada level sedang hingga tinggi serta kondisi } \\
\text { kawasan yang dominan sudah terbangun dan } \\
\text { beberapa sudah padat, maka untuk mewujudkan } \\
\text { pengembangan konsep TOD memerlukan } \\
\text { penambahan sedikit fungsi TOD pada ruang kosong } \\
\text { bahkan pembangunan kembali untuk } \\
\text { mengintensifkan kapasitas dan fungsi pelayanan } \\
\text { kawasan dalam kelompok ini. Beberapa hal } \\
\text { pendekatan pembangunan yang dapat dilakukan } \\
\text { yaitu : peremajaan kembali kawasan, penataan } \\
\text { lingkunga, serta menambah/ membangun } \\
\text { infrastruktur pendukung untuk layanan TOD (sesuai } \\
\text { dengan kriteria teknis dan prinsipnya). }\end{array}$} \\
\hline 4 & ST. Simpang Polda & & \\
\hline 5 & ST. Demang & & \\
\hline 6 & ST. Palembang Icon & & \\
\hline 7 & ST. Dishubkominfo & & \\
\hline 8 & ST. Pasar Cinde & & \\
\hline 9 & ST. Jembatan Ampera & & \\
\hline 10 & ST. Polrestabes & & \\
\hline 11 & ST. Jakabaring & New Growth Area & $\begin{array}{l}\text { Walaupun termasuk dalam arahan tipologi } \\
\text { pengembangan TOD pada level sedang, namun }\end{array}$ \\
\hline
\end{tabular}




\begin{tabular}{|c|c|c|c|}
\hline No. & Kawasan Transit & $\begin{array}{c}\text { Strategi } \\
\text { Pengembangan } \\
\text { Kawasan }\end{array}$ & Pertimbangan Penilaian \\
\hline 12 & ST. OPI Mall & $\begin{array}{l}\text { kondisi kawasan yang masih mendukung dengan } \\
\text { dominannya lahan belum terbangun maka untuk } \\
\text { strateginya bisa lebih terkonsentrasi terhadap } \\
\text { mewujudkan pengembangan kawasan TOD baru. }\end{array}$ \\
\hline
\end{tabular}

Ket : $\quad$ TOD Kota

TOD Sub-Kota

TOD Lingkungan

Tabel 9. Arahan Strategi Strategi Perwujudan Pengembangan Kawasan TOD Kota Palembang

\section{PENUTUP}

\section{Kesimpulan}

- Berdasarkan hasil analisis didapat 3 jenis tipologi TOD yang dapat dikembangkan pada kawasan transit koridor LRT Kota Palembang. Yang pertama adalah TOD Kota, TOD Sub Kota dan TOD Lingkungan.

- Terkait dengan prioritas pembenahan, 4 prinsip TOD (diversity \& destination, density, distance \& design serta demand management) menjadi penting dan menjadi dasar untuk pembenahannya. Bila dalam pembenahan dibagi dalam beberapa tahap, maka berdasarkan tingkat kepentingannya dari ke 4 prinsip TOD tersebut, yang paling penting sebagai awal untuk diwujudkan adalah prasyarat diversity \& destination. Kemudian prasayat density serta distance \& design, selanjutnya bila ke 3 nya sudah selesai maka barulah untuk melakukan manajemen/ pengaturan terhadap prasyarat demand managementnya.

- Arahan pengembangan TOD Kota yaitu di kawasan transit ST. Jembatan Ampera, dengan prioritas utama pembenahan yaitu pada perwujudan prinsip density.

- Arahan pengembangan TOD Sub Kota yaitu dikawasan transit :

ST. RSUD Provinsi $($ Prioritas pembenahan $=$ prinsip distance \& design $)$,

ST. Simpang Polda,

ST. Demang,

ST. Palembang Icon,

ST. Dishubkominfo,

ST. Pasar Cinde (prioritas pembenahan = prinsip demand management $)$,

ST. Polrestabes (prioritas pembenahan $=$ prinsip diversity \& destination $)$,

ST. Jakabaring (prioritas pembenahan $=$ prinsip diversity \& destination dan density) dan

ST. OPI Mall (prioritas pembenahan = prinsip density).

- Arahan pengembangn TOD Lingkungan yaitu di kawasan transit ST. Asrama Haji \& ST. Telkom

- Terdapat 3 strategis pengembangan kawasan transit dalam mewujudkan pengembangan TOD tersebut, antara lain : 1). Redevelopment site yakni dengan melakukan peremajaan serta penataaan kembali terhadap bentuk kawasan dengan maksud untuk menambahkan fungsi baru dan fasilitasnya; 2). Infill development site yakni dengan melakukan pembangunan $\&$ pengembangan TOD dengan memanfaatkan ruang-ruang kosong dalam kawasan; 3). New growth area yakni pembangunan baru dengan konsep TOD pada kawasan yang relatif masih kosong. 
- Arahan strategi pengembangan kawasan dengan Infill development site di 2 kawasan transit yaitu : ST. Asrama Haji dan ST. Telkom.

- Arahan strategi pengembangan kawasan dengan redevelopment site \& infill development site di 8 kawasan transit yaitu ST. RSUD Provinsi, ST. Simpang Polda, ST. Demang, ST. Palembang Icon, ST. Dishubkominfo, ST. Pasar Cinde, ST. Jembatan Ampera dan ST. Polrestabes.

- Arahan stretegi pengembangan kawasan dengan new growth area dilakukan di 2 kawasan transit yaitu ST. Jakabaring \& ST. OPI Mall.

- Beberapa prioritas pembenahan dan strategi tersebut, dapat diadopsi untuk tahap perencanaan, desain kawasan TOD yang akan dikembangkan dengan tetap memperhatikan hasil pencapaian nilai indeks total prinsip TOD dan kriteria teknis pengembangan TOD sesuai dengan acuan normatif Permen ATR/BPN No. 16 tahun 2017 tentang Pengembangan Kawasan Berorientasi Transit (TOD).

\section{Rekomendasi}

- Penyesuaian terhadap rencana tata ruang yang lebih detail seperti RDTR yang kemudian tujuan, sasaran dan substansi utama dalam penyusunan dokumen tersebut untuk diselaraskan dengan isu dan kriteria teknis arahan pengembangan TOD dikawasan transit koridor LRT Kota Palembang.

- Penekanan terhadap konsep pengembangan tata ruang terhadap wilayah yang bersinggungan dengan kawasan transit LRT. Terkait perlunya harus mengandung unsur mix used fungsi kawasan sehingga menjadi kompak dan lebih diminati, intensifikasi pemanfaatan dan pembangunan kawasan dan bangunan serta pengembangan ruang-ruang yang lebih dominan untuk pemanfaatan pada pergerakan orang tanpa kendaraan bermotor dengan harapan dapat menekan penggunaan kendaraan pribadi dan beralih ke angkutan umum serta pergerakan dengan berjalan kaki/ bersepeda.

- Dengan telah adanya layanan angkutan massal berbasis rel yaitu LRT di Kota Palembang Sumatera Selatan, maka bila seyogyanya dalam urutan pilihan daya dukung mobiltas masyarakat kota selain menggunakan kendaraan pribadi yaitu berjalan kaki/ bersepeda, angkutan umum feeder (angkot dan sejenisnya), BRT dan LRT maka pebenahan yang segera dibutuhkan antara lain : a). Peningkatan akses dan fasilitas untuk berjalan kaki/ bersepeda dalam kawasan TOD, b). Reformasi angkutan umum (kondisi kualitas nyaman \& aman serta kuantitas moda \& jalur trayek layanan) dan c). Penyediaan Jalur khusus BRT.

- Terkait dengan keberadaan angkutan Transmusi yang dianggap sebagai salah satu layanan bis bersifat transit (BRT) maka untuk mengoptimalkannya perlu untuk melakukan pembuatan jalur khusus untuk layanan Transmusi. Dengan mempunyai jalur khusus akan mendorong efektifitas layanan serta efisiensi waktu dan dapat memenuhi standar ideal yang layak sebagai salah satu layanan BRT disuatu kota (ITDP,2016).

\section{DAFTAR PUSTAKA}

Calthorpe, P. (1993). The next American metropolis: Ecology, community, and the American dream. Princeton architectural press. 
JURNAL KACAPURI

JURNAL KEILMUAN TEKNIK SIPIL

Volume 3 Nomor 1 Edisi Juni 2020

Cervero, R. (2014). Transport Infrastructure and the Environment in the Global South: Sustainable Mobility and Urbanism. Journal Of Regional And City Planning, 25(3), 174-191. doi:10.5614/jpwk.2015.25.3.1

El Garouani, A., Mulla, D. J., El Garouani, S., \& Knight, J. (2017). Analysis of urban growth and sprawl from remote sensing data: Case of Fez, Morocco. International Journal of Sustainable Built Environment, 6(1), 160-169. Available at : http://dx.doi.org/10.1016/j.ijsbe.2017.02.003

Feudo, F. L. (2014). How to build an alternative to sprawl and auto-centric development model through a TOD scenario for the North-Pas-de-Calais region? Lessons from an integrated transportation-land use modelling. Transportation Research Procedia, 4, 154-177. Available at : https://doi.org/10.1016/j.trpro.2014.11.013

Institute for Transportation \& Development Plan., (2017), TOD Standart, New York, www.itdp.org

Kamruzzaman, M., Baker, D., Washington, S., \& Turrell, G. (2014). Advance transit oriented development typology: case study in Brisbane, Australia. Journal of Transport Geography, 34, 54-70. Available at: http://dx.doi.org/10.1016/j.jtrangeo.2013.11.002.

Kustiwan, I. (2011). Pengendalian Perkembangan Fisik Kota (Penanganan Urban Sprawl). Bunga Rampai Pembangunan Kota Indonesia Abad 21 Edisi 2

Peraturan Menteri Agraria dan Tata Ruang Nomor 16 tahun 2017 tentang "Pedoman Pengembangan Kawasan Berorientasi Transit (TOD)". Kementrian Agraria dan Tata Ruang

Suzuki, H., Cervero, R., \& Iuchi, K. (2013). Transforming cities with transit: Transit and land-use integration for sustainable urban development. World Bank Publications.

Van, E. Der. Kraben., (2017). Managing Sustainable Urban Growth, Paparan Seminar, Semarang 